\title{
A Review of Nostalgic Marketing
}

\author{
Rubo Cui \\ Jinan University Management School, Guangzhou, China \\ Email: cuirubo99@163.com
}

Received 8 January 2015; accepted 25 February 2015; published 28 February 2015

Copyright (C) 2015 by author and Scientific Research Publishing Inc.

This work is licensed under the Creative Commons Attribution International License (CC BY).

http://creativecommons.org/licenses/by/4.0/

(c) (i) Open Access

\begin{abstract}
This paper discusses the nostalgia in marketing. Nostalgia as a way to communicate with consumers has already been more and more favorable in the marketing field. Previous studies have shown that nostalgia has achieved good results in the field of marketing. This article will present the concepts and mechanism of nostalgic marketing, the target group and strategies of nostalgic marketing. Finally we summarized the myth in nostalgic marketing practice, so as to provide feasible suggestions for the successful implementation of nostalgia marketing in the future.
\end{abstract}

\section{Keywords}

Nostalgic Marketing, Mechanism, Target Group, Marketing Strategy

\section{Introduction}

With the speeding pace of modern life, recalling the past is also a kind of luxury. Someone go straight ahead, someone stopped to look backward, also some people indulge in the past sadness and joy. Stopping to look back occasionally, complex emotions will fill atrial — this is nostalgia. Nostalgia is a hot topic in today's society, and also widely exists as an emotional experience. Today nostalgia is playing an important role in marketing. Through nostalgia, we can effectively communicate with consumers, in this way we can achieve the purpose of marketing. In fact in the marketing practice at home and abroad, more and more companies use nostalgic psychology of consumers as a marketing strategy. Through market segmentation and nostalgic strategy implementation, we can make nostalgic marketing as medium to express and promote nostalgia culture, and to make our marketing more successful [1]. The influence nostalgia marketing involves both spiritual culture and other fields, nostalgic goods. For example, T-shirts and nostalgic snacks are popular in youth; nostalgic tourism is in unprecedented prosperity; nostalgic movie, animation, and games are all of important value in the field of marketing. With the deepening of the research on consumer behavior, nostalgia emotions influences on consumer behavior are gradually be taken seriously. 


\section{The Overview of Nostalgic Marketing}

\subsection{Overview of Nostalgia}

Nostalgia is a kind of complex emotional state longing for the past. In the west, nostalgia is a compound word is derived from the combination of Greek words nostos (back home) and algos (pain), the literal meaning of the word is the pain caused by taking flight home. Researches on nostalgia began in western countries. The concept of nostalgia was first put forward by a Swiss army doctor. Later along with the continuously go deep into people's understanding of nostalgia, nostalgia connotation from a kind of disease symptoms slowly evolved into a state of mood, then become a concept which can be widely used in the research field and also extend from medicine to psychology, sociology, marketing and consumer behavior. Now, scholars generally believe that consumers nostalgia is a kind of love toward things, these things are common when they were young. They think that nostalgia is not only a sad, bittersweet reaction, but also includes the love of the past things, and people can produce nostalgia even they have not experienced the era.

\subsection{Consumer Nostalgia and Nostalgic Marketing}

Consumer Nostalgia is a concept corresponds with Nostalgia Marketing. Holbrook [2] thought that consumer nostalgia is a passion for people, places and things form the past. And these things were common (popular, trendy or spreading) in people when they were young (early adulthood, adolescence, childhood or even before birth). Former scholars studied the conceptual structure of consumer nostalgia, now more recognized nostalgia include: 1) Personal Nostalgia, direct personal experience and memory; 2) Interpersonal Nostalgia, personal non-direct experience and memory, which can come from parents, common experience and memory et al.; 3) Cultural Nostalgia, memory of groups; 4) Virtual Nostalgia, based on books, video materials and other non-direct experience of a group of and memory [3]. In general, individual and collective nostalgia can inspire consumers a richer emotional experience. We usually measure consumers' nostalgia with scale. Holbrook's nostalgia scale which is prepared in 1993 now is widely used as a concurrency measurement scale , the scale constituted by eight effective factors with a good reliability coefficient is very large $(\alpha=0.81)$ [4]. In addition, Mckechnie's Antiquities Hobby Scale and Taylor's Experience Scale are also used to measure the tendency of consumer nostalgia; Pascal's Nostalgia Scale of 10 items measures consumer attitudes toward advertising and brand, and also measure purchase possibilities of the customers. In China, Lu measured consumer nostalgia in Chinese context, get extraction 14 items from foreign nostalgic attitude scale, including personal nostalgia, personal and social nostalgia, and family nostalgia $(\alpha=0.884)$. On this basis, He developed a consumer nostalgia scale based on the background of Chinese consumers with thematic method, comparative analysis with the West nostalgic Scale validity showed that Chinese consumers' nostalgic scale has good validity and reliability [5].

Corresponds with the consumer nostalgia, nostalgia marketing is a marketing tactic refers to companies give consumers a certain nostalgic element in marketing activities to stimulate and activate consumers' nostalgia, evoke memories deep inside the consumer, and eventually promote consumers' buying behavior. First, there must be a nostalgic reminiscence of marketing elements to stimulate consumers, resonating with consumers, and then to have the desire and motivation to buy certain product or service [6]. From the nature of sense, marketing is more of a nostalgic emotion. It sells more than just the product itself, but also of goods carried by emotions. Marketing researches about a lot of nostalgia marketing, its position in the business world has become increasingly prominent.

\subsection{The Mechanism of Nostalgia Marketing}

Holbrook think consumers mixed feelings of nostalgia, and nostalgia is the prevalence of young people on their own favorite things. Mining or create nostalgia factor in the product is the key to successful nostalgia marketing. Nostalgia marketing is not simply add a nostalgia factor to the product, but to use this factor to combine business and products, to mine products brand potential nostalgic elements, and endow the product brand with the significance of the scene or characters, in this way we can stimulate consumers' nostalgic feelings, and to promote and sell more on this basis, and finally achieve good sales results [7].

So it is how a sense of nostalgia be evoked? How is nostalgia marketing work? To answer these questions, some scholars carried out for many studies in-depth [8]. According to the model of consumer behavior, consumer behavior can be divided into three reaction process, they are emotional reaction, cognitive reaction and 
behavioral reaction, corresponding to the field of nostalgia marketing, consumer behavior is consist of nostalgic emotional reactions, nostalgic cognitive responses and nostalgic behavioral responses three stages:

Stage I: Nostalgic Emotional Reaction. At this stage people awaken their inner memory through contact direct or indirect with merchandise and to contact themselves and the merchandise occurs by attitudes and emotions. Research shows that feelings can be evoked by diversity nostalgia factors, including people, events, etc. These factors can be both physical stimulation and invisible stimuli [9].

Stage II: Nostalgic Cognitive Reaction. Dominated in nostalgia, people being affected by physiological and psychological mechanisms which produce positive or negative attitude toward goods, and we generally call it nostalgic cognitive responses. Typically, when people think the situation in the past to have a more positive perception than it is now, people tend to feel positive nostalgia, whereas a negative perception of nostalgia will occur. Nostalgia product preferences are usually active in positive nostalgia, the affirmation and love of the past can inspire people's preferences of products, and then to meet their emotional needs through the consumption of nostalgia product. It is a stable foundation of the successful implementation of nostalgia marketing.

Stage III: Nostalgic Behavioral Reaction. At this stage people start to take nostalgic emotion and cognition into action. The attitude of people towards the past (cognitive variables) will linked with behavior of buying nostalgia product. Research shows that the more people love the things in the past, the more possible they will buy the product [10]. With the passing of time, people buy products to keep contact with the past, and maintain self-continuity, which is the direct cause of nostalgia consumption.

In summary, nostalgia marketing first inspired nostalgia emotion, then nostalgia emotion transformed into nostalgia cognition, and eventually nostalgia behavior is formed. People buy more nostalgia product to fulfill the role of nostalgia marketing.

\section{Target Group of Nostalgia Marketing}

Nostalgic marketing is to share a common experience of person who have the common memories to be resonating with consumers, but the experience may be differ from times and regional characteristics. Each generation has its unique symbols on the nostalgic memories, and different people have different needs to fulfill. In response to these characteristics and needs, the target group of nostalgia marketing can be divided into the following categories:

- Experienced old people. In general, people of older mental age tend to be more nostalgia. Especially in the retirement phase of the elderly, there is no learning, career and family problems, they were in a relatively stable stage, there is more time to think and remember the past. At the same time, the accumulation of the vicissitudes of life in the elderly, there are deep feelings of life, their way of thinking and doing things have been fixed for the previous form, when they could not understand or adapt some of the phenomena of modern society, they will be in their own memories and have their own way to solve the problem, and they also bringing back memories of people and things with their contemporaries. So they like to use some of the old things they ever used when they were young, such as friendship cream, traditional shopping bags. More than that, advertising can also use the old streets, old folks and other scenes evoke memories of the elderly on the previous experience, in order to achieve nostalgic marketing purposes.

- Group of Special Experience. People have special experience or background, may have a convergence in some respects. Experienced the founding of New China spent his whole life in the old revolutionary response to Chairman Mao's call of going to the countryside, those who with special experience or background in groups can cause them to recall the past, things that resonate. There will be a common sense of identity, a sense of intimacy preference. Special experience and background gave them nostalgic capital. Veterans bars and youth shops emerged everywhere in our country, lifetime nostalgia in those places. Camouflage clothing, kettle and military package may act as media of nostalgia. Nostalgia consumption is occurred unknowingly when talking with old friends.

- Groups Away from Previous Environment. Because of this population's living environment change or they are departure from the prone discomfort, they like to keep the original preferences with strong nostalgia. Such as overseas students, businessmen and overseas Chinese, away from their homes make them more conscious of nation, they miss motherland, family and friends, and everything belong to the original life, nostalgic elements can easily touch their psychological and trigger nostalgic consumption. And those who are impoverished now but originally from scratch, poverty groups, despite a prosperous life, living environ- 
ment has changed much, they still keep the original in some aspects of life, such as consumer habits et al. Businesses may take advantage of these features to seize consumers, stimulate nostalgia and produce a multiplier effect in marketing.

- Young People. These people face to rapid social changes, the enormous psychological pressure always make them feel confused and uneasy; on the other hand they were born in an individual, free and open society, confident and novelty is their nature. Two sides of modern society shape their dual nature nostalgia, nostalgia in their hearts to bring stability and a sense of belonging, but also become fashionable and popular elements. Miss the look of ink handwriting with a letter of communication, miss postcard postmark behind the card with holiday greetings, and miss the feeling to look towards the light image. Regardless of basic necessities, nostalgia pervasive force in the interpretation of the young, which is also provide a big stage for the prevalence of nostalgic marketing.

\section{Strategy of Nostalgia Marketing}

Nostalgia marketing focuses on trigger consumers' nostalgia awareness and produce nostalgia to inspire subsequent nostalgia behavior. To achieve this path, businesses must first select the appropriate stimuli to evoke feelings of nostalgia, namely take appropriate marketing strategy to achieve marketing effectiveness and purpose. It is generally believed that nostalgic marketing strategies consist of character nostalgia, event nostalgia and collective nostalgia.

\subsection{Character Nostalgia}

Family member and friends can evoke the warmth of memories. Nostalgia character is major stimulus of consumers, so companies can take advantage of the nostalgic element in the design of the product. The game we play in our childhood may as a reminiscent of childhood friend with joy; Li Lei and Han Meimei is too reminiscent of those in English class; "Those Years", "To the Youth" and other films reminiscent of love sweet time when we were young; The song "Where Did the Time Go" reminiscent of a child to live together with their parents, such as the good old days. In commercial areas, the March cold medicine advertising intimate care utilization as a friend to a friend with the background song of Zhou's. In this way, we can resonate with consumer, create intimate feeling of nostalgia; some farm paradise restaurant launched unique dishes of mother's taste to stimulate the taste buds of consumers, in order to achieve a nostalgic marketing purposes.

\subsection{Event Nostalgia}

Everyone's life has some memorable memories of the special day or time, such as weddings, festivals or school life. When people live unhappy, they will miss former life; when people are in a foreign land, they will evoked by special memories at a particular time, that's what "Every Festival Pro" means. Therefore, the proper use of festivals and events specific to the design element of nostalgia can often get good publicity. For example, Taobao and other online trading platforms are all doing well in nostalgic marketing. They often choose certain topics such joy to do promote their product. They are giving consumers concessions, at the same time own brand happy philosophy passed everyone, while greatly improving the sales.

\subsection{Collective Nostalgia}

Collective nostalgia refers to a group of shared same memory, in its capacity as an entry point for marketing, promotional activities undertaken nostalgia can play a good role in marketing. In some time the popular things are quiet, after a very long period of time, they may well be popular again, which is a popular emotional and full of memories. For example, Viking, Transformers, Black Sergeant, Li Lei and Han Meimei and other classic characters, can cause joint tenderness memories of young people. Though the use of collective nostalgia, you can find and evoke memories of this group together and resonate effect. In order to increase product sales, business can carry out marketing nostalgic design elements. Wedding planning with bike carriage for transportation, dress the bride and groom with the Red Guards, marry the bride with a chair, etc. will all receive unexpected results [11].

All in all, nostalgic strategies can be varied. If businessmen use nostalgia strategy properly, the benefits may be substantial. Nostalgia Marketing can also establish a firm foundation of loyalcustomer group. 


\section{Approach of Nostalgia Marketing}

Nostalgia marketing strategy focuses on guiding businesses to select the appropriate combination of nostalgia stimulus and commodities, and nostalgic marketing approach is focusing on how to combine this product in front of consumers. Summaries the previous research and have an overview of business practices, there are two main ways in current nostalgia marketing.

\subsection{Nostalgic Packaging}

Nostalgic packaging refers to designers taking advantage of people's memory of the past. It is consciously create a "sense of history" or "original sense" on the product packaging. These packaging always use natural materials, and the decoration is rough simply, to present a unique historical flavor [12]. Sixties and seventies of the last century, people were used to brown paper bag book, and then simply printed with black ink on the title, giving a solemn earthy feel. Some businesses are now packed notebook with craft paper. You may feel its vicissitudes, in this way to evoke memories of a distant era. This package has been widespread among consumers, sales have increased significantly. Luzhou closure altar purple vintage bottles using quaint, traditional oval bottle, the bottle at the ancient carved, giving a heavy sense of history, marking its year-old Chen possession, mellow and unique. For the purpose of stimulating consumers to buy the product, nostalgic packaging design companies may grab the consumer with the elements of a common memory, the memory of this show tangible symbol in front of consumers through packaging, in order to achieve its aim to stimulate purchases.

\subsection{Nostalgic Advertising}

The famous American advertiser Robin Chomsky said: "I firmly believe that in order to form a first-class advertising we must inject passion in advertising, so consumers would not forget later.” Previous studies of nostalgia show that ads triggered consumers' goodwill to advertisement and brand, and also help to improve consumers' willingness to buy. Nostalgic type of advertising appeals to emotion, focusing on the emotional connection with the companies, products, services, and add nostalgia factor in the design of advertising may attract consumers' specific attention, arouse their nostalgia, stimulate their desire to buy [13]. In practice, companies can tap a typical characteristic of the era to evoke the traditional habits of consumers' dusty collective memory, resulting in beautiful and warm feelings, resulting nostalgia buying behavior. Southern black sesame paste ad is classic nostalgic advertising as the little boy buried eat sesame paste scenes, with profound implication of the advertising slogan “A Surge of Flavor, A Ray of Warmth” and Flirting narrow alley make sesame paste the Kami attractive vividly demonstrated in front of consumers. This is not only a successful ad that makes Southern black sesame paste known by everyone, but also for enterprises to bring excellent sales performance.

\section{Summary}

Nostalgia nostalgic consumption has made waves, and rising with the increasing signs. Major companies and businesses have adopted a nostalgic marketing approach in order to achieve the purpose of increasing sales. But now many of nostalgia marketing case in some of these are failed attempts; some errors have been reflected in the individual companies and businesses’ nostalgia marketing.

- All merchandise can do nostalgia marketing. Nostalgic goods, is an emotion goods. Consumers buy goods in a feeling of nostalgic, so nostalgic marketing of goods and products must be able to remember things in the consumer docking. This is the only way to stimulate consumers to buy the product. Consumers buy those nostalgic commodity is actually for his past life experiences and self-consolation prize, therefore not all goods are fit to do nostalgia marketing. Actually marketing of goods should have a choice of nostalgia.

- Goods which are no longer useful now cannot succeed in nostalgia marketing. "Old” means relative; for consumers, "old" is often "new"; this is right nostalgic charm here. Even people recognizing past earth room and tile are uninhabitable on rational, the past coins are no longer in circulation, comic past was black and white, the past snack is no longer a delicious, but people still feel very cordial and fresh, so even now some commodities seems moot, rendered nostalgic elements can still get a good marketing.

- Nostalgic marketing can only target in consumers who experienced nostalgia. Consumers' nostalgia is divided into four types, namely, personal nostalgia, collective nostalgia, nostalgia and virtual cultural nostalgia. Collective nostalgia and virtual cultural nostalgia which are due to non-virtual direct experience and expe- 
rience generated. The current popular "People’s Communes Big Canteen”, also attracted the younger generation to patronize. For young people, although they have not experienced that kind of time, through book, film or television works they see and hear things during that period; in order to pursue a freshness, and even fashion, although not personally experienced, they still will be a choice of their trendy consumption.

- Nostalgia can just focus on "old" without innovation. Consumers have nostalgia does not mean that companies need not to consider the actual needs of consumers. In fact, only in the form of the old and inject into the new meaning and emotion, and then assisted in upgrading the product, can nostalgia marketing be completely accepted by consumers. Xi'an appliance market launched nostalgic appliances in 2011, refrigerators with old photographs of colors, interior features and design is quite modern and innovative. These nostalgic products have won a lot of pro-consumer gaze. Looking at our nostalgia market, many companies can seize nostalgia selling point, but the inherent quality of products and support services is not much better. Many companies simple use of nostalgia element, but not inject fresh elements to fulfill consumers' modern demands; therefore marketing effectiveness cannot be forever. Today's nostalgia products must reflect modern nostalgia, so nostalgic modern consumer consumption and natural fit, and "new" and "old" complement each other, in order to obtain a good income.

- Nostalgia is only affected by internal factors; therefore nostalgia can only cater to nostalgia marketing needs of consumers. The formation of this misunderstanding is unclear of the mechanism of nostalgic marketing. To make nostalgia marketing successful, the first step is to evoke nostalgic feelings of consumers, thus producing nostalgia cognitive, and then nostalgic transformed to consumer behavior. Therefore, marketing is not just nostalgia passive meet; the psychological needs of consumers, businesses and businesses can also seek the perfect combination of goods and nostalgia factor, to "take the initiative".

Here we can see a successful example of Coca-Cola. Compared to other countries, consumers in China are more consistent with memories, and thus cooperates are more likely to resonate with consumers branded content.

Coca-Cola China on the occasion of 35th anniversary return to Chinese mainland, raised the topic of nostalgia on multiple platforms and launched a series of topics of interactive communication.

The interactive discussion of \# taste of memories \# on the micro blogging platform, the micro-channel platform to tap the brand's own history story, then watercress station called fans' memories produce UGC, CocaCola China succeeded in the formation of social networks between brands and consumers emotional loop.

In summary, nostalgia marketing as a new marketing tool, used properly can not only bring considerable income to the business, but also could establish and maintain a stable of loyal customer base which can make an important contribution to the enterprise or business. Due to the above-mentioned errors nostalgic marketing makes some businesses fail achieving the desired results; therefore, in order to make the size of nostalgia marketing lasting and gradually expanded, we must return to the nostalgic product itself. This requires companies and businesses develop nostalgic marketing strategies, select proper nostalgic mode, and focus on the analysis of their products and optimizing the product and nostalgic points. Only in this way can we avoid these nostalgic marketing mistakes, and let nostalgia strategies play an important role in the marketing field.

\section{References}

[1] Gao, H. and Lu, T.H. (2006) Western Consumers Nostalgia Research Review. Foreign Economies and Management, 28, 26-33.

[2] Holbrook, M.B. and Schindler, R.M. (1991) Echoes of the Dear Departed Past: Some Work in Progress on Nostalgia. Advancesin Consumer Research, 18, 330-335.

[3] Holak, S.L., Havlena, W.J. and Matveev, A.V. (2006) Exploring Nostalgia in Russia: Testing the Index of Nostalgia. Proneness. European Advances in Consumer Research, 7, 33-40.

[4] He, J.X. (2010) How Do We Remember the Past? Context of Chinese Culture Nostalgia Consumers Tend to Develop Validated Scales Compared with Nostalgic Product Research and Purchasing Behavior. Marketing Science, 10, 45-49.

[5] Shen, L. (2012) Research on Consumer Loyalty of Nostalgic Marketing. MBA Thesis, Nanjing Normal University, Jiangsu.

[6] Guo, G.Q. (2009) The General Theory of Marketing. People of China University Press, Beijing.

[7] Zhu, H.F. (2013) Promotional Activities Planned and Executed. China University of Technology Press, Beijing.

[8] Zhuo, S.Y. (2011) Nostalgic Consumer Behavior Patterns and Path Analysis. Consumer Economy, 27, 69-71. 
[9] Wildschut, T., Sedikides, C., Arndt, J. and Routledge, C.D. (2006) Nostalgia: Content, Triggers, Functions. Journal of Personality and Social Psychology, 91, 1-59. http://dx.doi.org/10.1037/0022-3514.91.5.975

[10] Sierra, J.J. and McQuitty, S. (2007) Attitudes and Emotions as Determinants of Nostalgia Purchases: An Application of Social Identity Theory. Journal of Marketing Theory and Practice, 15, 99-112. http://dx.doi.org/10.2753/MTP1069-6679150201

[11] Wang, G.L. and Zhang, W. (2011) Marketing Strategy Based on Consumer Nostalgic Brand. Enterprise Economy, 11, 46-49.

[12] Zhang, Y. and Sun, M.G. (2011) Marketing Strategy Based Nostalgic Feelings of Nostalgia Business. Shanghai Management Science, 6, 67-70.

[13] Liu, H.Y. and Zhou, Z.M. (2009) Nostalgia Marketing In Turbulent Era. Sales and Marketing, 34, 52-54. 
Scientific Research Publishing (SCIRP) is one of the largest Open Access journal publishers. It is currently publishing more than 200 open access, online, peer-reviewed journals covering a wide range of academic disciplines. SCIRP serves the worldwide academic communities and contributes to the progress and application of science with its publication.

Other selected journals from SCIRP are listed as below. Submit your manuscript to us via either submit@scirp.org or Online Submission Portal.
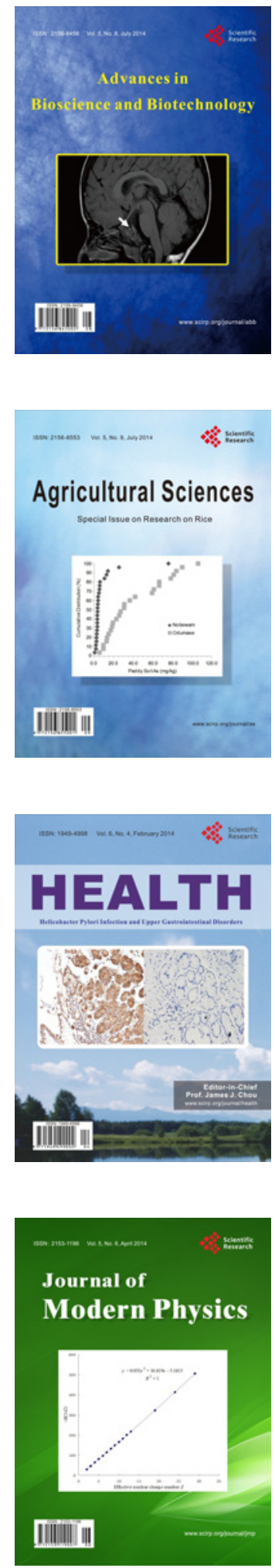
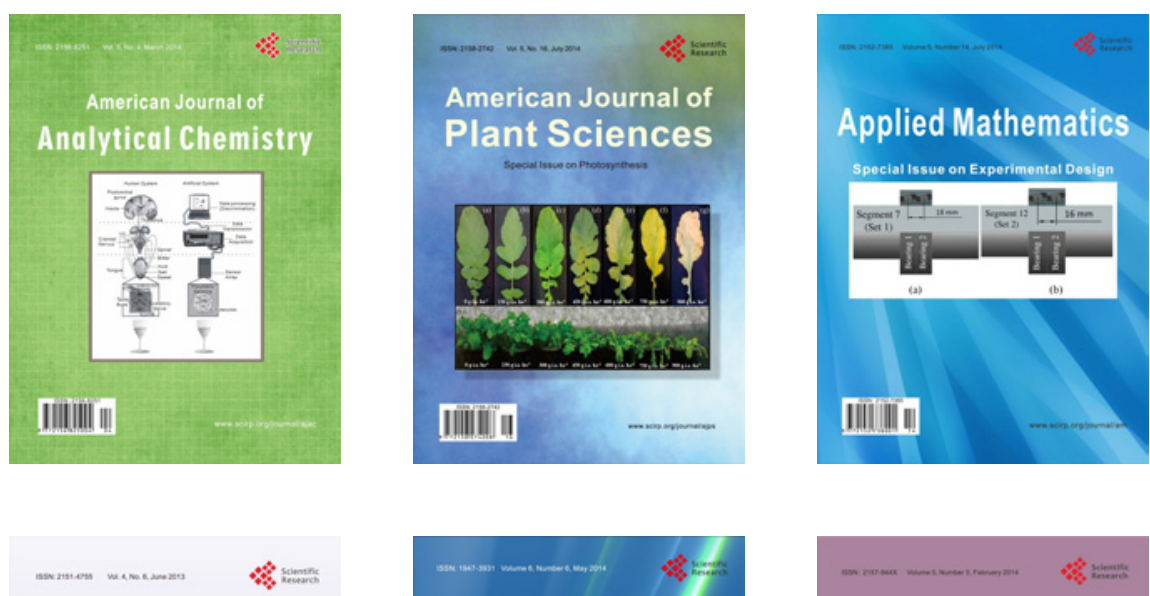

Creative Education
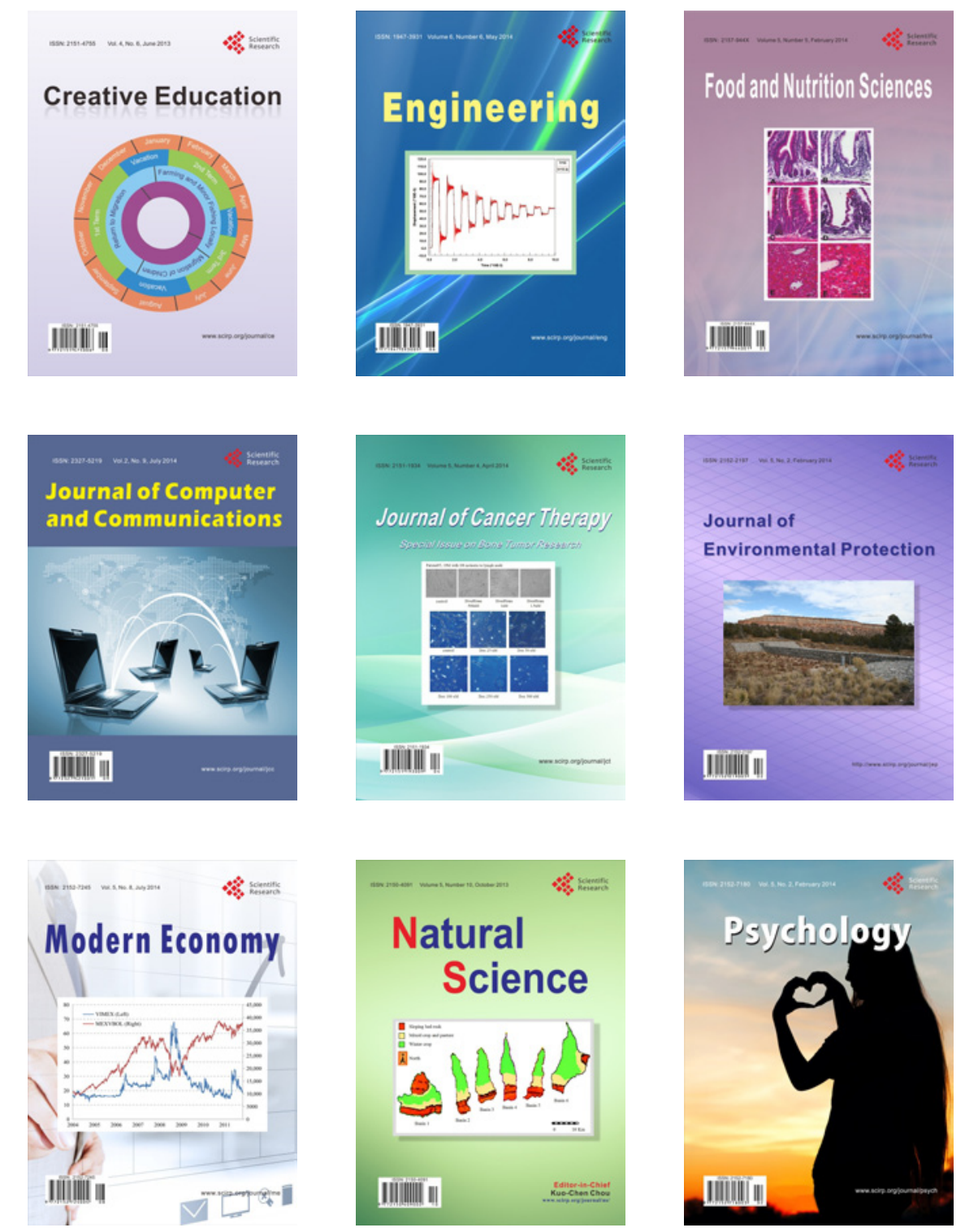